\title{
CAMPAIGN CONTRIBUTIONS AND GOVERNMENT GRANTS
}

\author{
by \\ Christian James Cox
}

A thesis submitted in partial fulfillment

of the requirements for the degree

of

Master of Science

in

Applied Economics

MONTANA STATE UNIVERSITY

Bozeman, Montana

April 2015 
CCOPYRIGHT

by

Christian James Cox

2015

All Rights Reserved 


\section{ACKNOWLEDGEMENTS}

I would like to thank Dr. Carly Urban, Dr. Christiana Stoddard, and Dr. Timothy

Fitzgerald. Their helpful comments and guidance were vital to completing the paper. 
TABLE OF CONTENTS

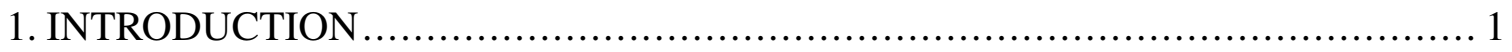

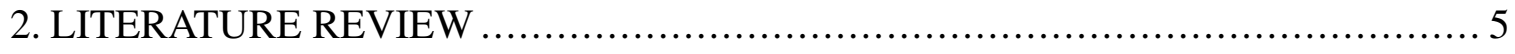

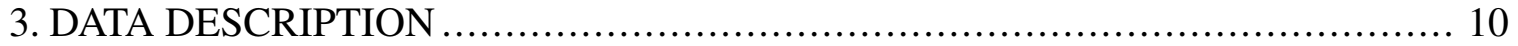

Nonprofit Data............................................................... 10

Contributions Data ............................................................. 11

Name Matching Process ........................................................... 11

Data Restrictions ............................................................ 13

Descriptive Statistics ...................................................... 15

4. EMPIRICAL ANALYSIS .................................................... 17

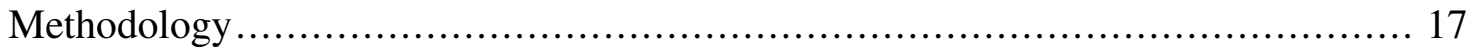

Fixed Effects Results............................................................ 19

Political Heterogeneity ........................................................ 20

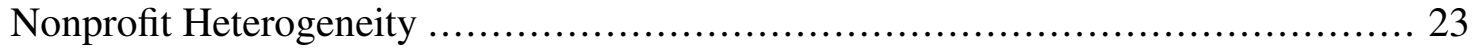

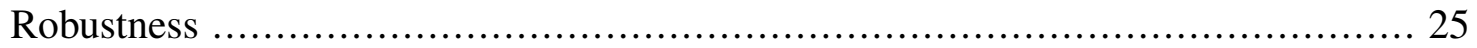

Number of Key Employees................................................. 26

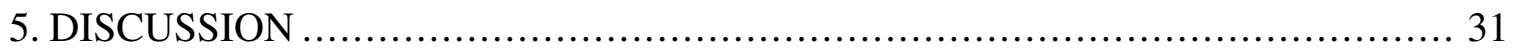

REFERENCES CITED ................................................................ 34

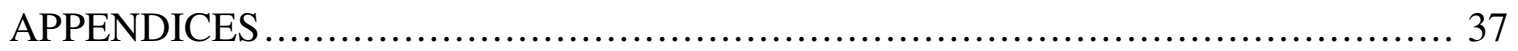

APPENDIX A: Descriptive Statistics............................................ 38

APPENDIX B: Regressions................................................... 44 


\section{LIST OF TABLES}

Table Page

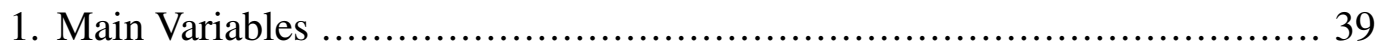

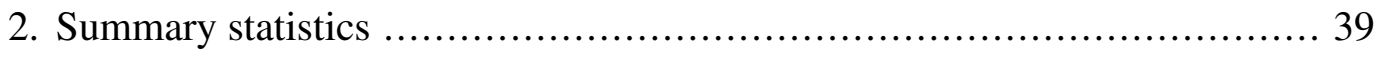

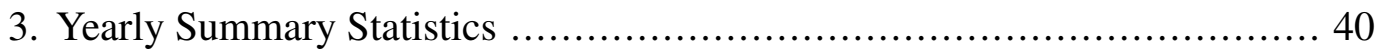

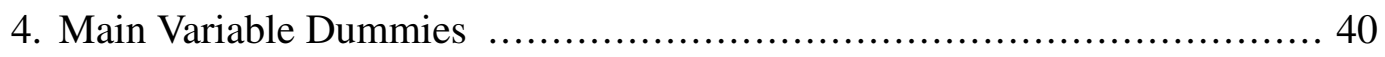

5. Covariate Correlations ......................................................... 41

6. Estimating Grants From Pooled Contributions ............................. 45

7. Estimating Grants From Candidate Characteristic Specific Contributions .... 46

8. Estimating Grants From Contributions By Nonprofit Type ................. 47

9. Estimating Grants From Contributions By Nonprofit Type .................. 48

10. Estimating Grants From Contributions Using Alternative Specifications..... 49

11. Alternate Specifications Investigating The Number of Key Employees....... 50 


\section{LIST OF FIGURES}

$\begin{array}{lll}\text { Figure } & \text { Page }\end{array}$

1. Average Grants per Contribution Percentiles .................................... 2

2. Yearly Contribution and Grant Averages ...................................... 42

3. Log Grant Histogram …...................................................... 42

4. Log Contributions Histogram ..................................................... 43

5. Number of Names Histogram ................................................... 43 


\begin{abstract}
This paper investigates the extent to which campaign contributions influence government grant allocation. I compare federal election campaign contributions from nonprofit officers, directors, trustees, and foundation managers to the government grants those nonprofits obtain. This unique dataset combines nonprofit financial audits with FEC contributions records by matching employee names. Aggregating individual contributions and yearly audits, I construct a nonprofit panel, and I find an association between government grants and nonprofit employee contributions. Results indicate a robust positive relationship with a substantial return to contributions.
\end{abstract}




\section{INTRODUCTION}

According to the Urban Institute (2013), the U.S government appropriated grants and contracts to about 56,000 nonprofit organizations in 2012 totaling $\$ 137$ billion. In 2011, one-third of all revenue for 501(c)(3) public charities came from federal, state, and local grants and contracts. When government funds decrease, competition for grants increases. As nonprofits must apply for a limited number of grants, an incentive to use other means of acquiring grants arises. Leaders within nonprofit organizations may have political influence or the funds to acquire such influence. One channel of potential influence is the relationship between these individuals and members of Congress, or more specifically, the influence of campaign contributions on politicians. Upon receiving the contributions, Congressmen may reward donors by helping the donor affiliated nonprofits obtain grants. If this proposed relationship exists, then nonprofits that would not otherwise receive grants may acquire them. This paper looks at 501(c)(3) charitable organizations, which are nonprofits with restrictions on their political behavior. These nonprofits are prohibited from making significant political contributions as an organization.

Consequently, political contributions by the nonprofit may be driven by individual contributions from within the organization.

This leads to the paper's central question: Do individual campaign contributions relate to government grant allocation? Further inquiry into this question is motivated by Figure 1 on page 2 , in which grants are compared to contribution percentiles. The average grant for nonprofits at the 25 th percentile of contributions is about one million dollars less 
than for nonprofits at the 75 th percentile of contributions. The overall positive slope is suggestive of some relationship between grants and contributions, with significant heterogeneity for different levels of contributions.

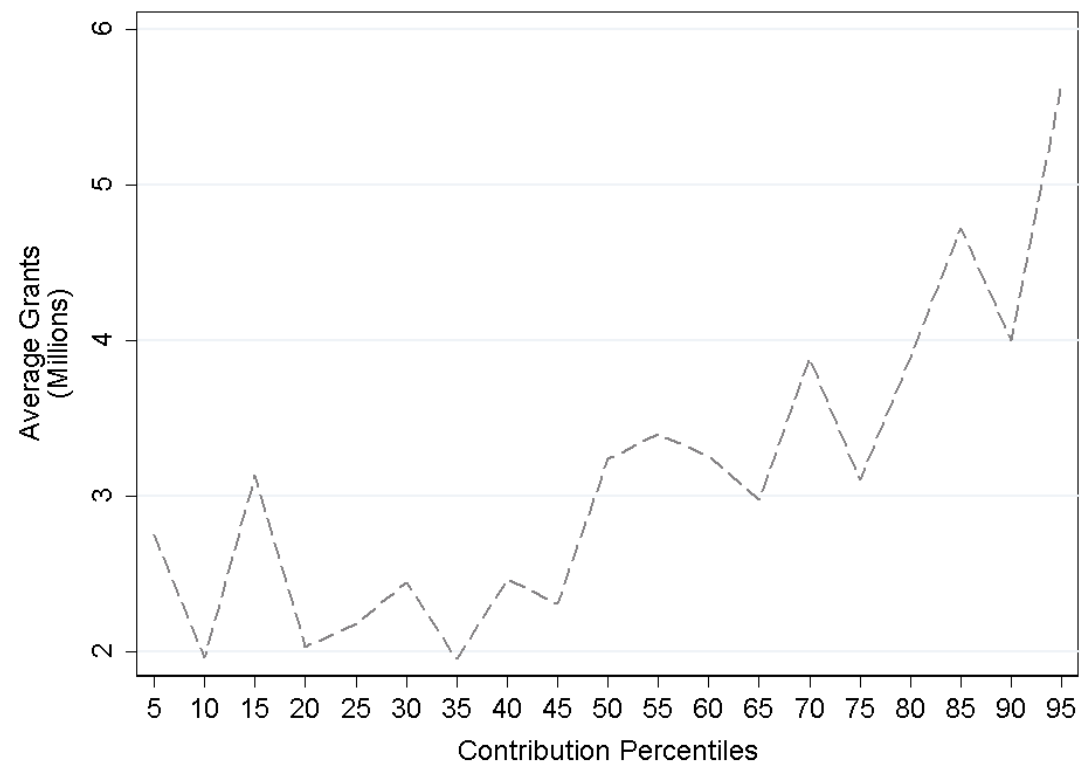

Figure 1: Average Grants per Contribution Percentiles

Current political economy research considers the influence of for-profit firm and PAC campaign contributions on Congressional behavior and reaches a variety of conclusions on whether contributions alter politicians' votes (Baron, 1989; Snyder, 1990, 1992, 1993; Lopez, 2001; Ansolabehere et al, 2003; Cooper et al, 2010; Campante, 2011). This paper contributes to the political economy literature by identifying government grants to nonprofits as an area that individuals may influence with campaign contributions.

The nonprofit literature investigates the political activity of nonprofits, and primarily, the effect of government funding on nonprofit activity (Regan \& Oster, 2000; Chaves et. al, 2004). Furthermore, current nonprofit research also identifies grants as a 
competitive market where nonprofit characteristics affect grant allocation (Luksetich, 2007; Ashley and Faulk, 2010). The unique dataset in this paper, which matches nonprofit agents to their contributions, introduces a new approach to analyzing nonprofits. It also contributes to the literature by expanding the knowledge of how grant allocation is determined and which nonprofit characteristics may be influential in affecting this allotment.

I measure the proposed nonprofit political influence through campaign contributions from nonprofit officers, directors, trustees, and other key employees. I construct this dataset by combining nonprofit financial audits to the Internal Revenue Service $^{1}$ with Federal Election Commission contributions records by matching employee names and zip codes from the audits to individual campaign contributors. This gives me a panel of nonprofits, with employee aggregated contributions, and three main sets of information. First, it includes the contribution characteristics of that specific individual. ${ }^{2}$ Second, it contains the candidate election result information. Third, it includes the nonprofit dataset, which has the variables that nonprofit organizations report in their yearly financial audits.

The time-constant characteristics of nonprofits likely affect grants and contributions within a nonprofit and not controlling for these factors may bias contributions. I estimate a nonprofit fixed effects model, including election cycle fixed effects, and control for the financial variables that the nonprofit literature considers

\footnotetext{
${ }^{1}$ From The Urban Institute GuideStar-NCCS National Nonprofit Research Database (1998-2003).

2Including the time range of the contribution, the amount of money, and the specific candidate or committee for that contribution.
} 
significant in affecting grant levels (Schiff \& Weisbrod, 1991; Ashley \& Faulk, 2010;

Kerlin \& Pollak, 2011). Results indicate a positive relationship between contributions and grants.

The paper proceeds as follows. Section 2 is a brief review of the relevant papers in the nonprofit and political economy literatures. Section 3 details the construction of the panel with further information on the specifics of the exact data structure. Section 4 contains the empirical analysis, including the methodology and regression results. Section 5 discusses the limitations of the findings and concludes the paper. 


\section{LITERATURE REVIEW}

Multiple papers explore the marketplace of grants and the nonprofit characteristics that affect grant amounts (Andreoni \& Payne, 2003; Luksetich, 2007; Ashley \& Faulk, 2010; Lecy \& Slyke, 2012). The primary subject includes the relationships between nonprofit finances and grants. This paper contributes to the literature by studying the interaction between government grant allocation and campaign contributions. Beyond recognizing that nonprofits seek grants, understanding the drivers behind potential grant lobbying may help the empirical analysis and theoretical justification.

Ashley \& Faulk (2010) determine that higher debt ratios (ratio of liabilities to assets) and fundraising ratios (ratio of fundraising costs to public-related revenues) in grant-seeking nonprofits result in smaller grant amounts. While Ashley and Faulk look at foundation based grants and this paper considers government grants, nonprofit financial health may be important for government grants as the government is privy to the IRS audits.

The characteristics of the grant marketplace affect how nonprofits behave. Schiff \& Weisbrod (1991) argue that decreasing government grants causes nonprofits to increase commercial activity for revenue, while according to Kerlin \& Pollak (2011), most nonprofits do not replace reduced government grants with increased commercial revenue. They argue that growth in demand for nonprofit services and number of nonprofits puts pressure on revenue streams. Similarly, Luksetich (2008) suggests a simultaneous relationship between government funding of nonprofits and nonprofit density. Higher 
government funding increases the number of nonprofits in a state, and fundraising activities positively relate to grant availability.

There is substantial sociological and public policy research on the relationship between nonprofit political activity and government funding (Netting, 1982; Salamon, 1995; Regan \& Oster, 2000; Berry, 2003; Chaves et al., 2004; Boris \& Steuerle, 2006; Powell \& Steinberg 2006). Some of these studies investigate how receiving government aid potentially affects nonprofit behavior, such as board decisions or public assertions supporting a candidate. The literature also identifies "Get The Vote Out" campaigns and political pulpit preaching as sources of nonprofit political influence.

Chaves et al. (2004) ask whether receiving government funding affects nonprofit political activity, specifically whether the aid suppresses it. ${ }^{3}$ They determine that receiving government aid decreases suppression for church congregations and has a null effect for other nonprofits. Similarly, Regan \& Oster (2002) determine that government funding affects board behavior and composition. Receiving government contracts leads to higher government oversight of nonprofit activity and consequently the decisions of the board. ${ }^{4}$

There is an extensive literature on the relationship between firms and politicians, specifically on the return to campaign contributions (Baron, 1989; Snyder, 1990, 1992, 1993; Lopez, 2001; Ansolabehere et al, 2003; Cooper et al, 2010; Campante, 2011). The literature is filled with mixed results and varied ways of defining returns to those firms. ${ }^{5}$

\footnotetext{
${ }^{3}$ They ask whether churches become more or less political after receiving funding. Church surveys ask the congregations about their church services and whether speaking out or distributing voter guides occur. They also use a representative panel of nonprofits surveyed in Minneapolis, and ask whether nonprofits engage in lobbying after receiving funding.

4They found that nonprofit contractors in New York City who receive government contracts shift board activity from fundraising to financial monitoring and advocacy.

${ }^{5}$ Access to politicians is a common benefit of contributions, but quantifying it is often regarded as difficult.
} 
My inquiry is different from the existing literature primarily because I consider 501(c)(3) nonprofit contributions at the individual level and government grants as the payoff rather than for-profit company or 501(c)(4) nonprofit contributions and legislation. Papers that discuss individual level contributions are important as individual contributions are my measure of influence, and numerous papers question whether policy-buying even exists in campaign contributions.

Ansolabehere et al. (2003) argue that campaign contributions are merely a form of political participation and not policy-buying, primarily because most contributions are from individuals. They contend that studies that argue in favor of effective vote buying do not sufficiently consider the economic significance of their results and quantifying the effect is difficult. Similarly, Campante (2011) argues that individuals recognize their negligible effect on political outcomes through their campaign contributions. He considers campaign contributions as merely a form of political consumption, as an investment mentality would be aimless. Fremeth et al. (2012) find that individual campaign contributions significantly increase when individuals assume leadership roles in firms. The politics of the contributors do not significantly change, rather just the magnitude of their overall contributions to candidates and political action committees.

This literature often groups contributors into two categories, the investor and the ideologue. The former expects a return on their investment while the latter is ideologically driven to support a candidate. If the key employees within nonprofits are contributing merely for the increase in government grants, then they fit into the investor category.

This is due to the simultaneity of contributions and congressional behavior, and the inability to know whether a politician's specific actions are at the behest of a particular contributor. 
However, they may have two distinct sets of contribution types, grant-oriented contributions and politically-minded contributions. A contributor may give to one candidate with a grant return in mind, while giving to another for merely ideological reasons.

On this subject, Snyder (1992) argues that vote buying can be seen as a long-term investment, in which donors try to gain career-long favor with a politician. He finds heterogeneity in the payoff of contributions and behavior between the investment-driven and ideologically-driven contributors. For example, older politicians receive less support, as the career-long return for the contributors is likely lower than giving to a younger candidate. Snyder (1993) determines that an investor-driven contribution simple asset market model is effective at describing campaign contributions. Snyder uses a model that considers politicians exchanging favors for campaign contributions. He finds that contributors give to candidates in accordance with the candidates' probabilities of winning.

Cooper et al. (2010) investigate the return to firms from giving to candidates. Firms that contribute to multiple candidates in the same state that win elections have future abnormal stock returns. Claessens et al. (2008) also find a positive effect on stocks ${ }^{6}$ and Lopez (2001) finds a positive effect on subsidies. ${ }^{7}$ Firms can yield financial gains from favorable government policy and the nonprofits analyzed in this paper may be

\footnotetext{
${ }^{6}$ They show that firms in Brazil with high campaign contributions get higher stock returns than firms that donated less, and this return increases if the candidate wins. Part of the benefit is that firms who support winners on average gain better access to finance from banks.

${ }^{7} \mathrm{He}$ finds that campaign contributions significantly increase agricultural subsidies. Lopez concludes that the rent-seeking behavior of the agricultural lobby effectively alters input subsidies.
} 
viewed similarly.

Certain nonprofits, likely by sector, may gain substantially depending on the political party in power. For example, a Democratic President may be more likely to increase grant allocations for environmental nonprofits. Knight (2006) determines that certain firms can significantly gain or lose in equity returns depending on what party or candidate wins an election. He puts certain firms into camps based on which candidate they would likely support, denoting them politically sensitive firms, and analyzes their stocks before and after the election. The firms' campaign contributions align with the proposed political camps. 


\title{
DATA DESCRIPTION
}

\author{
Nonprofit Data
}

The NCCS-GuideStar National Nonprofit Research Database contains digitized information on 501(c)(3) public charities that filed Form 990s or 990-EZ from 1998-2003.8 The grant variable comes from the "Government contributions (grants)" value on the forms. I extract the names from the "List of Officers, Directors, Trustees, and Key Employees" value on the 990 forms. ${ }^{9}$ These employees and their contributions are used because these employees are mostly high-level management, so they are the most likely individuals within a nonprofit to make individual campaign contributions (Fremeth et al, 2012). Also, nonprofit financial audits list their names, making these names the most accessible in creating a database. The number of names listed on the financial audits varies between nonprofits. ${ }^{10}$

I select a variety of other variables from the 990s. I consider total expenses and number of paid employees as indicators of size. I use three ratios as proxies for financial health and efficiency for nonprofits; The debt ratio divides total liabilities by total assets and is an indicator of financial solvency. The fundraising ratio is made by dividing fundraising expenses by direct and indirect public support (neither include grants), and

\footnotetext{
${ }^{8}$ Church affiliated organizations, certain political organizations, and nonprofits with less than $\$ 50,000$ in gross receipts are not required to file 990s. The database contains the majority of variables from the forms.

${ }^{9}$ The IRS defines "key employees" as: "Any person having responsibilities or powers similar to those of officers, directors, or trustees. The term includes the chief management and administrative officials of an organization (such as an executive director or chancellor) but does not include the heads of separate departments or smaller units within an organization."

${ }^{10}$ The number of names listed on audits per year ranges from 1 to 2,339. The variation within nonprofits between years is not substantial when removing nonprofits with more than 100 names. The 90th percentile of names is at 50 , with the median at 20.5 .
} 
measures how effectively the nonprofit raises funds. The administrative ratio divides administrative expenses by total expenses and measures how much the nonprofit spends on their administration.

\section{Contributions Data}

The individual contribution files come from the FEC for the 1998-2002 elections. The files contain each contribution from an individual to a federal committee of at least \$200.11 The contribution limits per election (primary/runoff/general each) for 1998-2002 is $\$ 1,000$, increasing to $\$ 2,000$ on January 1st, 2003 (FEC Information Division). The vast majority of contributions are $\$ 3,000$ or lower for the entire election cycle. ${ }^{12}$ The individual contributions are unique at the committee level by report type ${ }^{13}$ by election cycle level. Committee and candidate information also originates from the FEC. ${ }^{14}$

\section{Name Matching Process}

The nonprofit dataset has 5,595,463 names and I construct a "cleaner" name variable that condenses the number of names down to $3,072,051$. This reduction is primarily driven by the same person having slightly different name values in the original

\footnotetext{
${ }^{11}$ Committees are allowed to submit values lower than \$200 (FEC Public Records Office), explaining the $1.8 \%$ of observations lower than $\$ 200$ in the datasets, and I drop them.

${ }^{12}$ Values higher than $\$ 3,000$ may be explained in numerous ways (FEC Information Division). First, a contribution check may be written by only one individual but the contribution is associated with others (e.g. spouse). Second, a candidate may give money to their own campaign without restriction. Third, individuals can give to joint-fundraising committees. A contribution to a joint committee is associated with each candidate from that committee, so the value per candidate in the summary dataset is over-stated.

${ }^{13}$ Time-frame of contributions, typically quarterly, monthly, or pre/post primary.

${ }^{14}$ The names, state, district, and party of these candidates are recorded in the FEC candidates file and I use the committee ID to match the contributions to candidates.
} 
name variable across years. ${ }^{15}$ The majority of dropped and altered names stem from regular expressions usage. ${ }^{16}$ I generate separate first and last name variables and I drop those missing either. I also remove any first and last name combination with a length less than 4. Most names with smaller lengths are not "real" names, in the sense that the above operations make the name unusable. ${ }^{17}$ I consider all contributions from the same name with the same 3 digit zip code to be from the same person, which introduces a source of measurement error. For example, all John Smiths from zip code 922 are considered the same person, which means I overestimate contributions for individuals with common names. ${ }^{18}$ The final dataset matches $5.7 \%$ of nonprofit names to FEC names. ${ }^{19}$

I take the range of years that a specific name appears on the nonprofit audits and match their name to all elections within those years. I associate all contributions by that individual during that time-frame with their respective nonprofit. ${ }^{20}$ If an individual works for several nonprofits I assign both nonprofits the same contributions amount. To match the yearly nonprofit values to election cycles, I add the 1998-1999 (2000-2001/2002-2003)

\footnotetext{
${ }^{15}$ The original name variable in the FEC dataset has 1,976,009 and the new variable has 932,247. The decrease comes from name variations, missing zip codes, formatting issues, and company contributions.

${ }^{16}$ Titles and middle name positions are not consistent within each dataset. This is problematic as I remove titles and middle names and need specific regular expressions to match. I identify middle names by the different comma positions throughout the name, but names with multiple first or last names cause problems without dashes. Certain names have symbols like " $\&$ " and I drop those due to their matching problems.

${ }^{17}$ Short last names with abbreviated first names, such as "L. Na" would drop. This results in a potential source of culturally biased measurement error as I may under-represent Asian employee contributions by removing their names. The vast majority of names do not suffer from this problem so the magnitude of this measurement error is likely insignificant.

${ }^{18}$ This measurement error could be culturally biased as certain demographics may be more likely to have a common name. However the relation to grants is unclear. It may be the case that nonprofits with people with uncommon names are less or more likely to receive grants.

${ }^{19}$ I match on lastname, 3 digit zip code, and the first 4 letters of first name (to allow for slight variations like Kathy vs Kathryn). $5.7 \%$ of nonprofit cleaned names equates to $17.6 \%$ of FEC cleaned names, meaning that the matched nonprofit employees represent $17.6 \%$ of contributors.

${ }^{20}$ For example, a person will appear in 1998, and 2000-2002, but not 1999. I believe that their contribution may still influence the grants for the nonprofit in 1999 and thus associate that contribution with the nonprofit.
} 
nonprofit variables to match the 1998 (2000/2002) election contributions.

\section{Data Restrictions}

I construct the final dataset for analysis by making certain limitations. First, I limit the nonprofits to those that at some point received a grant ( $28 \%$ of nonprofits). Nonprofits with null values for grants (or contributions) during the entire time-frame will simply drop out in a nonprofit fixed effects model. Furthermore, nonprofits without grants may be systematically different than those with grants, and their contributions could be interpreted differently. Either those contributions are completely unrelated to grant allocation or those nonprofits unsuccessfully lobbied for grants in all three elections.

Second, I only include nonprofits with contributions in at least one of the three elections (37\% of nonprofits). Nonprofits with zero contributions and zero grants are likely an entirely disparate set of nonprofits that are not relevant. Nonprofits with no contributions and positive grants may acquire their grants through other channels, meaning their data generating process for grants may be substantially different, and are not pertinent to this analysis.

Third, I separate contributions between Presidential and Congressional races. Contributions to Presidents may have systematically different effects on grants than contributions to Congressmen. When I restrict the set of nonprofits to those with contributions, I initially consider only Congressional contributions as the narrowing factor. ${ }^{21}$ A technical issue is that only the 2000 election contains any significant

\footnotetext{
${ }^{21}$ Nonprofits that only give to Presidents are initially left out, as their decision to not use Congressional contributions as a source of influence justifies a separate analysis. I include Presidential contributions for
} 
Presidential contributions and the vast majority of nonprofits will simply have 0 values for two out of the three elections. Aggregate contributions will then spike in one year relative to the others, even if contributions to Congressional races do not change.

Fourth, I remove all contributions to non-candidate linked committees as the process of political influence for such committees is likely different than contributions directly to candidates (49\% of contributions). Furthermore, contributions to committees do not have the same set of campaign contribution limits, so comparing aggregated values is not appropriate. ${ }^{22}$ I initially allow joint fundraising committees, ${ }^{23}$ as those are subject to contribution limits per candidate in the committee, but I also run specifications excluding them.

Fifth, I limit the size of contributions by each individual to a committee.

Contribution values significantly higher than the contribution limit are problematic, in that identifying the individual and target of the contribution is difficult. Contributions by multiple individuals, by candidates, or through joint fundraising committees all cloud the interpretation and the easiest way to remove these issues is by simply capping the maximum contribution per individual in each election cycle. ${ }^{24} 99.2 \%$ of contributions are below $\$ 5,000$ and $2.1 \%$ of contributions are from joint fundraising committees.

Sixth, I restrict the set of nonprofits to those with a "reasonable" number of key employees listed on their audits. The large numbers may be due to technical issues rather nonprofits that also have Congressional contributions and consider the Presidential contributions separately.

${ }^{22}$ For example, the maximum contribution by an individual to a Senator's principal campaign committee for a given election is $\$ 1,000$, but some individuals give hundreds of thousands to their party's PACs.

${ }^{23}$ Joint fundraising committees are committees that raise funds for multiple candidates, where candidates share fundraising costs and split the contributions.

${ }^{24}$ I can use the same value as the contribution limit is constant through all three elections. I consider specifications limiting contributions to different values, ranging from $\$ 3,000$ to $\$ 10,000$. 
than systematic differences and the bias from removing these extreme instances is likely small (Less than 2 percent have extreme values). ${ }^{25}$ I consider multiple specifications restricting the number of names on audits. ${ }^{26}$ While such restrictions may bias the contributions' effect downwards, it reduces the bias from different number of available names.

Finally, I only consider nonprofits with sufficient coverage in terms of fiscal years. Due to my small time-frame, complete temporal coverage is important for any significant variation in a fixed effects model. Nonprofits must range for at least 5 of the 6 maximum years, and $85 \%$ of nonprofits (after the previous restrictions) meet this criteria.

\section{$\underline{\text { Descriptive Statistics }}$}

Descriptions and summary statistics of the main variables for the 28,988 nonprofits reporting positive grant and contribution amounts from 1998 to 2003, are on Tables 1, 2, and 3 on pages 39-40. The per election cycle average contribution per nonprofit is $\$ 1,689$, with a standard deviation of $\$ 4,738$. This high variance is due to some nonprofits with many members maxing out their contribution limits for many candidates and the non-trivial number of zeros (see Table 4). The average contribution for all positive contributions is $\$ 2,813$. Table 3 breaks down each variable by year as there is significant variation. For example, the difference in average contribution between 1998 and 2000 is

\footnotetext{
${ }^{25}$ The bias by keeping them in is potentially substantial as a nonprofit with over 100 names will likely have higher contributions than a nonprofit with 30 names, regardless of whether the former nonprofit is actually larger in terms of number of employees or financial characteristics.

${ }^{26}$ First, I simply remove nonprofits with more than 100 names (the 99th percentile). Second, in a different specification, I pick a fixed number of names, such as 25 , and pick random samples of names from each nonprofit to match to the contributions data. This gives each nonprofit the same number of names to match.
} 
$\$ 572$. Figure 2 on page 42 gives a bar graph for contributions and grants over three elections.

Log histograms of grants and contributions are on Figures 3 and 4 on pages 42 and 43. Grants are closely lognormal and log contributions have a long right tail. Large nonprofits list significantly more employees on their audits and the aggregate contributions are naturally larger. The spikes in the distribution for log contributions can be explained with the commonality of certain denominations in contributions. For example, $\$ 200, \$ 500$, and $\$ 1,000$ are popular choices for contribution amounts. ${ }^{27} \mathrm{~A}$ histogram of number of names is in figure 5 on page 43, capped at 100 names, and indicates that most nonprofits have fewer than 40 names.

Table 4 on page 40 gives dummy indicators for whether grants and contributions are greater than 0 for each nonprofit per election cycle. Observe that there are 6,760 out of the 86,832 observations where grants and contributions are 0 . Contribution's 0 values account for $40 \%$ of all observations. As noted before, there are no nonprofits with 0 in grants or 0 in contributions for the entire time period. Table 5 on page 41 gives the correlations of the main covariates. The lack of high correlations implies multicollinearity may not be a significant issue.

\footnotetext{
${ }^{27}$ Rounding values to the closest 10 or 100 does not produce such large spikes.
} 


\section{EMPIRICAL ANALYSIS}

In this section, I propose an empirical model to analyze the relationship between contributions and grants. I report a series of fixed effects models (4.2), investigate heterogeneous effects (4.3-4.4), and estimate alternative specifications to test result sensitivity (4.5-4.6).

\section{Methodology}

I estimate Equation 1, for nonprofit $i$ in election cycle $t$ :

$$
\ln (G)_{i t}=\alpha+\beta \ln (C)_{i t}+\delta \boldsymbol{F}_{i t}+\gamma_{t}+\sigma_{i}+\epsilon_{i t}
$$

$G$ is government grants received by nonprofits ${ }^{28} C$ is campaign contributions by key employees in those nonprofits; $\boldsymbol{F}$ includes financial variables of those nonprofits that may affect contributions or grants. $\beta$ represents the association between total nonprofit individual contributions and government grants. A positive $\beta$ coefficient would be consistent with the idea that nonprofits with more contributions see larger grants amounts.

I include fixed effects for each nonprofit to capture the time constant differences across nonprofits, such as reputation or managerial practices. These nonprofit characteristics likely affect grants and contributions and not controlling for such factors results in omitted variable bias. The reputation of a nonprofit within governmental departments likely affects their grant allocation, as respectable nonprofits may be more

\footnotetext{
${ }^{28}$ The log-normal distribution of grants motivates a log-log model.
} 
likely to acquire grants. Over the small-time frame in this panel, this sort of variation in grants may be soaked up by the nonprofit fixed effects. The time constant characteristics also relate to contributions as the hiring decisions by nonprofits may affect their aggregate contributions. I need to control for these factors as the types of nonprofits to have certain levels of contributions may also have certain levels of grants. Not controlling for these characteristics prevents identifying exogenous variation in contributions.

I also include fixed effects for each election to deal with potential differences in elections that affect all nonprofits. These factors likely affect grants as certain elections may see larger amounts of aggregate government funding. The election cycles also affect contributions as each election's idiosyncrasies likely relate to how much individuals contribute.

$\gamma_{t}$ estimates election cycle fixed effects and $\sigma_{i}$ estimates nonprofit fixed effects. With this model, I remove the variation in contributions that stems from nonprofit time-invariant characteristics, time-varying nonprofit characteristics related to grants through $\boldsymbol{F}$, and election cycle-specific variation. The variation in contributions that identifies $\beta$ is then the time-varying exogenous variation for each nonprofit and the variation in grants that affects contributions .

The $\boldsymbol{F}$ vector includes total expenses, the debt ratio, the administrative ratio, and the fundraising ratio. Total expenses may be the most valid financial indicator of size as it does not likely have a reverse causal relationship with grants. ${ }^{29}$ The three ratios may

\footnotetext{
${ }^{29}$ Public support is a size indicator similar to total expenses but it likely is affected by grants. As government grants are distributed out by politicians and voters elect those politicians, government grant allocation at the nonprofit category/cause/industry level is likely affected by voter opinion. This may be related to what the general public feels and consequently which nonprofits they give to and how much. Total expenses is not
} 
correlate with grants and contributions as higher quality nonprofits likely receive larger grants and quality may relate to their employees' political activity. As per the literature, I expect the debt ratio to be negatively correlated with grants, as it indicates a financially unstable nonprofit (Ashley \& Faulk, 2010). ${ }^{30}$ I predict the administrative ratio to be positively related, as a healthy nonprofit can afford to pay their management well and reduce pay without sacrificing program services. This differs from the literature that argues for a negative effect. ${ }^{31}$ The fundraising ratio may be negatively correlated with grants, if nonprofits with inefficient fundraising relate to grants (Ashley \& Faulk, 2010). ${ }^{32}$

\section{Fixed Effects Results}

The regression results from Equation 1 are reported in Table 6 on page $45 .^{33}$

Column 1 looks at contributions and grants with nonprofit fixed effects. The inclusion of year fixed effects and control variables in Column 3 decreases the contributions' coefficient sizes from Columns 1 and 2 without changing the standard errors, where all three estimates are precise at the 1\% level. The interpretation in Column 3 is that a $100 \%$ increase in contributions corresponds to a $1.5 \%$ increase in government grants, controlling for time invariant nonprofit characteristics, differences in election cycles, and financial

linked to grants in a similar fashion. Expenses can increase or decrease for a variety of reasons, irrespective of public attitudes. Also, expenses could increase to compensate for lack of revenue, such as increased fundraising expenses, or simply increase due to increased revenue.

${ }^{30}$ I divide debt ratio and fundraising ratio by 1,000 to align in magnitude with administrative ratio.

${ }^{31} \mathrm{~A}$ higher administrative ratio may indicate a poorly run nonprofit in the sense that the nonprofit is too concerned with enriching their management. This interpretation is supported to a certain degree in the nonprofit literature where higher administrative ratios lead to lower support from the general public, however the effect on grants is considered trivial (Ashley \& Faulk, 2010).

${ }^{32}$ Alternatively, since nonprofits with a high fundraising ratio are inefficient at raising and spending publicly raised funds, they may substitute to grants and be adept at acquiring them.

${ }^{33}$ All models cluster errors at the nonprofit level as I expect nonprofit distributions to be different. All models also include but do not report the constant. 
variables that may affect grants. The dollar interpretation, evaluated at the mean and conditional on giving, is that a $\$ 1$ increase in contributions corresponds to a $\$ 20$ increase in grants. ${ }^{34}$

Total expenses is positive and statistically significant at the $0.1 \%$ level, consistent with the literature. The debt ratio is statistically indistinguishable from 0 , which may indicate that the government does not consider this ratio when allocating grants, conditional on other nonprofit factors. ${ }^{35}$ The administrative ratio is positive and significant at the $0.1 \%$ level, which seems to lend credence to the argument that a higher administrative ratio can be considered a beneficial factor. Finally, the fundraising ratio is negative at the $5 \%$ level, supporting the idea that this indicator of nonprofit quality negatively relates to grants.

\section{Political Heterogeneity}

In this section, I estimate two models differentiating between the types of contributions based on political criteria. The incumbency status, election result, and electoral office for politicians may affect the association between contributions to those candidates and grants, as all three factors relate to the political influence of a politician.

In the first model, I separate contributions by combinations of the incumbency status and election result for candidates. ${ }^{36}$ Equation 2 below shows this model, with

${ }^{34}$ The mean nonzero contribution is $\$ 2,813$ and the mean nonzero grant is $\$ 3,653,804$.

${ }^{35}$ This is inconsistent with other literature that found the debt ratio to have a significantly negative effect on grants. These papers investigate foundation based grants which may have a different data generating process, where other factors determine the allocation.

${ }^{36}$ The win/loss distinction is for the election cycle to which the specific contribution is assigned. An incumbent losing in a primary is considered the same loss as losing in a general election. All candidates in open seat races are considered challengers (the FEC differentiates between challengers against incumbents 
contributions to incumbent winners (IW), incumbent losers (IL), challenger winners $(\mathrm{CW})$, and challenger losers (CL). The difference between this approach and Equation 1 is that I estimate this model with four separate contributions variables, and in Equation 1, I aggregate all four into one variable. This separation allows me to observe distinct effects across types of contributions.

$$
\begin{array}{r}
\ln (G)_{i t}=\alpha+\beta_{1} \ln \left(C_{\mathrm{IW}}\right)_{i t}+\beta_{2} \ln \left(C_{\mathrm{IL}}\right)_{i t}+\beta_{3} \ln \left(C_{\mathrm{CW}}\right)_{i t}+\beta_{4} \ln \left(C_{\mathrm{CL}}\right)_{i t} \\
+\delta \boldsymbol{F}_{i t}+\gamma_{t}+\sigma_{i}+\epsilon_{i t}
\end{array}
$$

This set of differentiation is partially motivated by Snyder (1992), who argues that older politicians would receive less support than younger politicians, as the younger politicians could yield longer-term returns to contributions. I test a similar hypothesis, whether grants received are higher for those who contribute to challengers compared to those who contribute to incumbents. ${ }^{37} \mathrm{~A}$ losing candidate, regardless of their incumbency status, will likely not be associated with higher grants. I expect contributions to winning challengers will relate to higher grants as Snyder argued the return on contributions to investors on young politicians is higher.

The results are in Column 1 of Table 7 on page $46 .{ }^{38}$ All contributions coefficients are statistically indistinguishable from 0 at the $10 \%$ and $5 \%$ levels, with the exception of and open seat race candidates).

${ }^{37} \mathrm{~A}$ challenger may have influence at the state or local level, especially if they held office at this level before running for federal office and could affect state or local grants regardless of winning. Thus, if grants are primarily state or local based, the differentiation between winners and losers at the federal level may not be meaningful.

${ }^{38}$ The decrease in 1,904 observations is due to the inability to match certain candidates, primarily challengers, to their election result. This failure comes from problems with name string matching. 
contributions to challenger winners, with a coefficient value of 0.014 . I can reject the hypothesis that contributions to winning challengers are effectively zero in their relation to grants, aligning with my expectation. To see if contributions to winning challengers have a distinct effect compared to contributions to winning incumbents, I test whether their coefficients are statistically different. The $\mathrm{p}$-value for this test is 0.575 , so I fail to reject that these two coefficients are statistically different. ${ }^{39}$ This result precludes ranking the different contributions by their relation to grants.

The second political heterogeneity model includes separate contributions by House, Senate, and Presidential candidates. It may be the case that only certain politicians can influence grant allocation and the specific authorities of the different branches may identify this heterogeneity. I expect that contributions to Presidential candidates will not see a positive effect and be less influential than contributions to Congressional candidates. Since Presidential elections have substantially higher overall contributions, the effect of specific contributions is smaller. Furthermore, individual nonprofits may have more trouble establishing beneficial relationships with Presidential candidates than with Congressional candidates, due to the smaller scope of Congressional elections. ${ }^{40} \mathrm{I}$ estimate Equation 3 with contributions to House (H), Presidential (P), and Senate (S) candidates.

$$
\ln (G)_{i t}=\alpha+\beta_{1} \ln \left(C_{\mathrm{H}}\right)_{i t}+\beta_{2} \ln \left(C_{\mathrm{P}}\right)_{i t}+\beta_{3} \ln \left(C_{\mathrm{S}}\right)_{i t}+\delta \boldsymbol{F}_{i t}+\gamma_{t}+\sigma_{i}+\epsilon_{i t}
$$

\footnotetext{
${ }^{39}$ I also test losing challengers against winning challengers and fail to reject that they are different.

${ }^{40}$ For example, a powerful nonprofit within one state likely has more influence over the state's Senators than the President, as the President is beholden to substantially more parties.
} 
The results are in Column 2 of Table 7 on page 46. I reject the null hypothesis of a zero value coefficient at the $5 \%$ level for the Senator contributions, with a coefficient of 0.013. The effect for Presidential candidates is not statistically significant, with a lower mean and slightly higher standard errors. ${ }^{41}$ To see whether I can compare the effects of contributions to different candidates, I test each type of contribution against each other. Senate contributions are statistically different than Presidential contributions at the $6 \%$ level, which indicates that despite the pronounced effect of Senate contributions, the Presidential contributions' standard errors are high enough to prevent differentiating between the two at a confidence level of $5 \%$ or above. ${ }^{42}$ Again, I cannot rank contributions by their type, preventing me from determining whether specific contributions drive the overall relationship.

\section{Nonprofit Heterogeneity}

The relationship between contributions and grants may vary across nonprofit size. In Columns 1 and 2 of Table 8, I restrict the samples to nonprofits above and below $\$ 2$ million in total expenses. The results indicate that nonprofits with total expenses below $\$ 2$ million see a statistically significant relationship at the $1 \%$ level, and the larger nonprofits do not see an effect. I fail to reject whether the two coefficients are statistically different

\footnotetext{
${ }^{41}$ As discussed in the data section, I restrict my panel of nonprofits to those with positive contributions to House and Senate candidates over one of the three elections. This excludes the nonprofits with only Presidential contributions. I reran this specification including those nonprofits and results are similar with small decreases in the effects of Senate and House contributions, but with an imprecise effect from Presidential contributions. Also, the Presidential contributions for 1998 and 2000 are just a few dollars, due to all the zeros, so only the year 2000 has normal levels of contributions.

${ }^{42}$ House and Senate contributions are not statistically different than each other, and House and Presidential contributions are not statistically different than each other.
} 
from each other, meaning it is unknown whether smaller or larger nonprofits are driving the pooled relationship. This uncertainty in the effect with large nonprofits seems counterintuitive, as one might expect the larger firms to visibly have more influence, as larger nonprofits may be able to hire more influential management. One possible explanation is that large nonprofits have other means of influence, or simply are more visible to government departments, and smaller nonprofits must rely on relationships with Congressmen. ${ }^{43}$

The relationship may also vary across nonprofit types, such as human services, environmental, etc. Congressmen, especially those on the Appropriations Committee, hold some influence over funding for federal departments. Politically sensitive nonprofits may see larger variation in grants and contributions between elections, as their funding may be at risk (Knight, 2006). ${ }^{44}$ I estimate six versions of Equation 1, separating each model by type of nonprofit. ${ }^{45}$

Results are presented in Tables 8-9 on page 47-48. The contributions coefficients for most types are too imprecise to give an estimate at the $10 \%$ level or above, with the exception of environmental/animal related nonprofits and human services nonprofits. The coefficient on contributions for the environmental/animal nonprofits is about 4 times as

\footnotetext{
${ }^{43}$ Another explanation is that larger nonprofits may have longer-term relationships with government departments and their grant levels do not vary as much compared to smaller nonprofits who may see large variation in grant levels year by year. It may also be the case that larger nonprofits simply do not seek government grants as actively as smaller nonprofits as their public donation or investment revenue may be sufficient, making campaign contributions a null factor for influence.

${ }^{44}$ For example, if the Republicans take over the Senate, the EPA may see a decrease in their budget to distribute out grants to environmental nonprofits.

${ }^{45}$ There are more than six categories of nonprofits, but I only include categories with more than 1,000 nonprofits. Identically, I could estimate a single fully interacted pooled model, but the separated models are more palatable in the regression output.
} 
large as the contributions coefficient in other specifications, which indicates the relationship is relatively strong for this subset of nonprofits. One explanation for environmental nonprofits seeing a strong effect is that environmental concerns may be considered secondary to other issues and funding for environmental causes could be the first to be cut when government funding decreases. I am unable to say that the effects of contributions by environmental nonprofits are greater than by all other nonprofit types, as a test comparing the environmental coefficient to all other types fails to reject the hypothesis that they are different, however the sample size for environmental nonprofits is only $3,222 .{ }^{46}$

\section{Robustness}

As discussed in Section 3.4, I make a series of decisions on how to limit my panel. In this section and in section 4.6, I estimate a multitude of models relaxing or restricting some of these rules as robustness checks, and I discuss potential measurement error in my contributions variable. The three specifications in Table 10 on page 49 are variations of the fixed effects model in Equation 1.

In Column 1, I regress grants on contributions to get a level-level interpretation and the result indicates that a $\$ 1$ increase in contributions corresponds to a $\$ 55$ increase in grants. The consistency of the positive and statistically significant coefficients on contributions between the log and level models is reassuring. In Column 2, I include state specific election cycle fixed effects. ${ }^{47}$ It may be the case that time-varying state-level

\footnotetext{
${ }^{46}$ I pool all other types of nonprofits into one model for this comparison.

${ }^{47}$ I only estimate this model on nonprofits in states with at least 300 nonprofits per state per election year.
} 
heterogeneity drives the differences in grants between nonprofits and could be related to contributions. ${ }^{48}$ Results show that contributions are robust to this inclusion, which indicates that state-year variation does not meaningfully identify contributions' effect on grants.

The specification in Column 3 of Table 10 differs from the previous datasets. As discussed in the data section, campaign contribution limits change how one interprets larger contribution values. To test whether my previous results are caused by the high amount oddities, I restrict contributions at the individual level to less than $\$ 5,000$ per election (primary/runoff/general combined) per candidate. Thus, the aggregated contributions values per nonprofit do not include contributions by individuals greater than $\$ 5,000 .{ }^{49} 99.2 \%$ of contributions to candidates are below this value so the results predictably do not change.

Results are also robust to including contributions from all other sources by zip code, number of nonprofits by zip code, FIPS level income and population per year, program service revenue, the closeness of Senate elections in the nonprofit's state, and with grants as a dummy variable in a linear probability model.

\section{Number of Key Employees}

A potential source of measurement error bias in my contributions variable is the number of key employee names listed on audits. If the number of names does not

\footnotetext{
${ }^{48}$ For example, if the California state government decided to change how they allocated state grants, the effect of contributions to California Congressmen may be different than other Congressmen.

${ }^{49}$ I also try contributions less than $\$ 3,000$ and $\$ 10,000$ and a specification removing joint fundraising committees, all with similar results.
} 
accurately identify the number of people giving within the nonprofit, then my contributions variable is inaccurate. How this error relates to grants affects the validity of the contributions variable. If this bias understates the contributions coefficient, then it is not a concern, but it may overstate the effect of contributions.

The first question is whether the error is serious or trivial. There may be little to no inaccuracy in the reporting of names, as the data are financial audits given to the IRS. In this case, I may be capturing the true set of "key employee" names, and consequently the true measured value of contributions by this set of nonprofit employees. ${ }^{50}$ Some studies find inaccuracies in the 990 reporting and how nonprofits define their expenses, particularly in how fundraising costs are calculated (Froelich \& Knopfle, 1996; Hager et al, 2002). There is variation in the types of names reported between years. For example, the phrase "board" in the job title is present in 5\% of 1998 names and present in $12 \%$ of names in 2003. If this is due to changes in federal reporting rules or a general shift in nonprofit management structure, then year fixed effects or state specific year dummies would likely control for the biasing effect. If this is the case, then the error is random at the nonprofit level and existence of such bias simply attenuates my coefficients, meaning current results are understated.

If the error is non-random at the nonprofit level, then does it correlate with grants and contributions in a way that would overstate my contributions coefficient? One way to investigate this is to predict the measured number of names with nonprofit variables that relate to contributions and grants, as in Equation 4. If the number of names meaningfully

${ }^{50}$ There may be other sources of measurement error in contributions, such as inaccuracies in the FEC files or flaws in my matching process. 
relates to nonprofit characteristics, then the mis-measurement may also vary similarly. The right hand side contains the number of employees, total expenses, direct public support, the debt ratio, the administrative ratio, and the fundraising ratio.

$$
\text { Names }_{i t}=\alpha+\beta \text { Employees }_{i t}+\delta \boldsymbol{F}_{i t}+\gamma_{t}+\sigma_{i}+\epsilon_{i t}
$$

The results are in Table 11 on page 50 in column $1 .{ }^{51}$ The number of employees, total expenses, and direct public support all relate positively to the number of names listed on audits. This is not surprising as these are all different indicators of nonprofit size and larger nonprofits tend to list more names on their audits. The debt ratio is negatively related to names, which indicates that more names on audits is correlated with lower debt values relative to assets. The number of names may be related to nonprofit characteristics in a non-random way, as the debt ratio is an indicator of nonprofit solvency. ${ }^{52}$

It is doubtful whether non-classical measurement error in contributions stems from number of names. Even if this is the case, the ability to directly include debt ratios in my model helps remove this potential source of error. The problem would still persist if the measurement error in the number of names is related to contributions and grants but not related to nonprofit time-invariant characteristics, time-varying characteristics at the state or national level, or the control variables included in my models. The measurement error

${ }^{51}$ The decrease in sample size is a result of some nonprofits missing the number of paid employees variable.

${ }^{52}$ The number of names being related to nonprofit solvency does not immediately seem meaningful, but if solvency is related to nonprofit transparency, then it may be intuitive. Perhaps more transparent nonprofits are more likely to report more names, meaning my contributions values are higher for more transparent nonprofits. Consequently, if I do not include debt ratios or number of names as control variables, higher grant values will be associated with higher contributions values when in fact higher contributions is merely a proxy for nonprofit transparency through number of names. 
could also be correlated with the measured value of names. ${ }^{53}$ This problem is also dealt with by simply including the number of names as a covariate. ${ }^{54}$

\section{Column 2 of Table 11 considers a differently constructed dataset than previous}

models. Instead of matching all available names from nonprofits to FEC records, I select a random sample of 25 names from each audit, including all names if less than 25. ${ }^{55}$ The purpose of this exercise is to negate the previous issue of biasing contributions by the number of names and bolster confidence in the construction of the contributions variable.

The resulting dataset only consists of the contributions from a small subset of names, which will underestimate contribution amounts by nonprofits with more than 25 names per year. The contributions coefficient is robust to this restriction.

Column 3 of Table 11 estimates the same model from Equation 1 with the addition of the number of total paid employees and the number of names listed on audits as covariates. ${ }^{56}$ The number of employees is a non-monetary indicator of nonprofit size and may be related to other nonprofit activity that relates to manpower. For example,

\footnotetext{
${ }^{53}$ For example, the more names a nonprofit lists, the higher the chance for errors. Or perhaps a smaller nonprofit is more likely to have errors as they may not have a professional accountant.

${ }^{54} \mathrm{As}$ the contributions variable is constructed from matching these names to FEC records, more names on audits means more names to match, and potentially more contributions. This is a potential source of bias as the nonprofit choosing how many employees to list will affect the size of aggregate contributions to which I assign them, so contributions may simply be a proxy for the number of names. The correlation between aggregate contributions per year and the number of key employees named on audits per year is 0.4 , which indicates that there is some variation in contributions that cannot be solely attributed to this problem.

${ }^{55}$ I also estimate specifications for only 10 and 15 employees with similar results. I also simply remove all nonprofits with more than 100 names for any given year. I also estimate a specification limiting the total number of employees listed across all years to between 38 and 75 (25th and 75th percentiles) and select 15 randomly as a way to only compare similarly sized nonprofits and avoid the extremely small and large nonprofits. Results are again robust, with a substantial increase in significance for this last specification. However, the available pool of nonprofits is only 8,277 instead of 28,988, as in the whole dataset.

${ }^{56}$ The validity of the number of employees variable on the audits is questionable, as some nonprofits list more "key employees" than total employees. However the "key employees" value does sometimes include board members, who may not be counted in the total paid employees figure.
} 
nonprofits may engage in "Get The Vote Out" campaigns, which may be more influential than contributions in affecting grants. Contributions are robust at the $1 \%$ level to these two additions, which indicates that the measured number of names listed on audits does not drive the relationship between contributions and grants. 


\section{DISCUSSION}

This paper asks whether there is a relationship between campaign contributions and government grants. The main threats to identifying this relationship are nonprofit characteristics that determine grant and contribution levels. I control for these problems by including nonprofit fixed effects and financial controls for nonprofit quality. I find a positive correlation between grants and contributions, robust to multiple specifications. However, even if the coefficients are statistically significant, are they economically meaningful? Increasing personal contributions from $\$ 2,813$ to $\$ 4,813$ relates to an increase in grants from $\$ 3,653,804$ to $\$ 3,693,804 .{ }^{57}$ A $\$ 2,000$ contribution for a $\$ 40,000$ (or $1.1 \%$ ) increase in grants is an economically substantial return.

There are hurdles to identifying the main effect. One problem is that the available data have a small time-frame. As the relationship between contributions and grants may operate over a longer time scale, this snapshot would not identify it, such as if larger grants follow higher contributions after four years.

Potential reverse causality precludes identifying the direction of the correlation. If grants drive contributions, these results may be evidence of payment for services rendered, or perhaps just an unintended positive externality for Congressmen. It is plausible that receiving grants may change nonprofit behavior, and the hypothesis that contributions lead to Congressmen helping nonprofits is less believable in the reverse direction. A Congressman would need to target certain nonprofits and possibly spend political capital to get those nonprofits grants, in hopes of increased campaign contributions. This is not a

\footnotetext{
${ }^{57}$ Using Column 3 from Table 6, evaluated at the mean, and conditional on positive contributions.
} 
likely occurrence, given the small magnitude of individual contributions, and this story may be more plausible at the industry level or for other forms of nonprofit influence. ${ }^{58}$

A main theoretical problem is clearly defining the actual relationship between grants and contributions. Papers within the contributions literature define their relationship more explicitly, which aids them in covariate selection. For example, some papers investigate whether PAC contributions affect Senator voting records. PAC contributions are an established form of influence that companies employ and Senator voting records is an accessible variable. An issue for this paper is identifying the channel of influence for grants. Is the source of influence votes on legislation affecting grants? The only meaningful influence of this form is whether the politician is on the Appropriations Committee, which affects departmental budgets, and chooses to affect the budgets of departments that may give those nonprofits grants. This seems to be a weak form of influence, as the nonprofit is not receiving a higher chance of getting a grant relative to similar nonprofits. Another source of influence that may be more likely, but is also impossible to measure, is whether the politician unofficially affects grant allocation decisions at either the federal, state, or local level (such as through back-room dealings). As this source of influence is so ill-defined, choosing an appropriate economic model is difficult.

Despite these issues, this paper accomplished the task of identifying an association

${ }^{58}$ Nonprofits may use "Get The Vote Out" campaigns as influence. However, 501(c)(3) nonprofits are legally barred from making candidate specific "Get The Vote Out" campaigns, only in a "neutral non-partisan manner". 501(c)(3) nonprofits are allowed to engage in a limited amount of political spending themselves or may simply establish 501(c)(4) nonprofits or political action committees. Also, nonprofits may not need to lobby legislators as they have untethered lobbying to agencies. 
between contributions and grants. The significant relationship justifies further inquiry into grant allocation. Regardless of the direction of the effect, this paper has found new information on the interaction between nonprofit political activity and government. Future work includes identifying more specific channels of influence, such as heterogeneous effects by Congressional committee membership. Separating grants by local, state, and federal grants is also likely required to find more specific associations. 
REFERENCES CITED 
[1] Ansolabehere, S., Figueiredo, J. M. D., And Snyder, J. M. Why Is There So Little Money in Politics? Working Paper 9409, National Bureau of Economic Research, Jan. 2003.

[2] Ashley, S., and FaulK, L. Nonprofit competition in the grants marketplace. Nonprofit Management and Leadership 21, 1 (Sept. 2010), 43-57.

[3] Berry, J. Empowering Nonprofits, May 2003. Urban Seminar Series on Children 's Health and Safety, Kennedy School of Government, Harvard University.

[4] Boris, E. T., And Steuerle, C. E. Nonprofits $\mathcal{E}$ Government: Collaboration $\mathcal{E}$ Conflict. The Urban Insitute, Jan. 2006.

[5] Bowen, W. G. The charitable nonprofits: an analysis of institutional dynamics and characteristics. Jossey-Bass Publishers, Oct. 1994.

[6] Campante, F. R. Redistribution in a model of voting and campaign contributions. Journal of Public Economics 95, 7-8 (Aug. 2011), 646-656.

[7] Chaves, M., Stephens, L., and Galaskiewicz, J. Does Government Funding Suppress Nonprofits’ Political Activity? American Sociological Review 69, 2 (Apr. 2004), 292-316.

[8] Claessens, S., Feijen, E., and Laeven, L. Political connections and preferential access to finance: The role of campaign contributions. Journal of Financial Economics 88, 3 (June 2008), 554-580.

[9] Cooper, M. J., Gulen, H., and Ovtchinnikov, A. V. Corporate Political Contributions and Stock Returns. The Journal of Finance 65, 2 (Apr. 2010), 687-724.

[10] Fremeth, A. R., Richter, B. K., and Schaufele, B. Campaign Contributions over CEOs` Careers. Working Paper 1203E, University of Ottawa, Department of Economics, 2012.

[11] GrøNBJERG, K. A. Using NTEE to classify non-profit organisations: an assessment of human service and regional applications. Voluntas: International Journal of Voluntary and Nonprofit Organizations 5, 3 (Oct. 1994), 301-328.

[12] Kerlin, J. A., And Pollak, T. H. Nonprofit Commercial Revenue A Replacement for Declining Government Grants and Private Contributions? The American Review of Public Administration 41, 6 (Nov. 2011), 686-704.

[13] Knight, B. Are policy platforms capitalized into equity prices? Evidence from the Bush/Gore 2000 Presidential Election. Journal of Public Economics 90, 4-5 (May 2006), 751-773.

[14] Lopez, R. A. Campaign Contributions and Agricultural Subsidies. Economics $\mathcal{E}$ Politics 13, 3 (Nov. 2001), 257-279. 
[15] Luksetich, W. Government Funding and Nonprofit Organizations. Nonprofit and Voluntary Sector Quarterly (Dec. 2007).

[16] Netting, F. E. Secular and Religious Funding of Church-Related Agencies. Social Service Review 56, 4 (Dec. 1982), 586-604.

[17] O'Regan, K., AND Oster, S. Does government funding alter nonprofit governance? Evidence from New York City nonprofit contractors. Journal of Policy Analysis and Management 21, 3 (2002), 359-379.

[18] Pettijohn, S. L. Nonprofit-government contracts and grants: Findings from the 2013 national survey. Urban Institute (Dec. 2013).

[19] Powell, W. W., And Steinberg, R. The Nonprofit Sector: A Research Handbook. Yale University Press, 2006.

[20] Romer, T., ANd SNyder, JR., J. M. An Empirical Investigation of the Dynamics of PAC Contributions. American Journal of Political Science 38, 3 (Aug. 1994), $745-769$.

[21] Schiff, J., ANd Weisbrod, B. Competition Between for-Profit and Nonprofit Organizations in Commercial Markets(*). Annals of Public and Cooperative Economics 62, 4 (1991), 619-640.

[22] SnYder, J. M. The Market for Campaign Contributions: Evidence for the U.s. Senate 1980-1986*. Economics $\mathcal{F}$ Politics 5, 3 (Nov. 1993), 219-240.

[23] SNyder, JR., J. M. Campaign Contributions as Investments: The U.S. House of Representatives, 1980-1986. Journal of Political Economy 98, 6 (Dec. 1990), 1195-1227.

[24] SNyder, JR., J. M. Long-Term Investing in Politicians; Or, Give Early, Give Often. Journal of Law and Economics 35, 1 (Apr. 1992), 15-43.

[25] Tinkelman, D., And Neely, D. G. Some Econometric Issues in Studying Nonprofit Revenue Interactions Using NCCS Data. Nonprofit and Voluntary Sector Quarterly 40, 4 (Aug. 2011), 751-761. 
APPENDICES 
APPENDIX A

DESCRIPTIVE STATISTICS 
Table 1: Main Variables

\begin{tabular}{|l|l|l|l|}
\hline Variable & Measure & Years & Source \\
\hline Grant & $\begin{array}{l}\text { Government grant, including local, state, } \\
\text { and federal, to a 501(c)(3) nonprofit orga- } \\
\text { nization }\end{array}$ & NCCS \\
\hline Total Expenses & Total operating expenses & $1998-2003$ & NCCS \\
\hline Debt Ratio & Liabilities over assets & $1998-2003$ & NCCS \\
\hline $\begin{array}{l}\text { Administrative } \\
\text { Ratio }\end{array}$ & $\begin{array}{l}\text { Administrative expenses divided by total } \\
\text { expenses }\end{array}$ & $1998-2003$ & NCCS \\
\hline $\begin{array}{l}\text { Fundraising } \\
\text { Ratio }\end{array}$ & $\begin{array}{l}\text { Fundraising expenses over direct and } \\
\text { indirect public support revenue }\end{array}$ & $1998-2003$ & NCCS \\
\hline Contribution & Individual campaign contribution & $\begin{array}{l}1998 / 2000 / \\
2002\end{array}$ & FEC \\
\hline
\end{tabular}

This table includes the main variable descriptions, their time-frame and their source. The NCCS is the National Center for Charitable Statistics and the FEC is the Federal Election Commission. The NCCS variables are yearly and the FEC variables are on election cycles.

Table 2: Summary statistics

\begin{tabular}{lcc}
\hline \hline \multicolumn{1}{c}{ Variable } & Mean & Std. Dev. \\
\hline Contributions & 1,689 & 4,738 \\
Grants (in thousands) & 2,997 & 24,505 \\
Total Expenses (in thousands) & 26,658 & 256,779 \\
Debt Ratio & 0.14 & 16.78 \\
Administrative Ratio & 0.16 & 0.15 \\
Fundraising Ratio & 0.45 & 19.72 \\
Number of Names & 26.45 & 27.54 \\
\hline \# Observations & 86,832 \\
\hline \hline
\end{tabular}

This table includes the main variable summary statistics, where contributions are the individual contributions by "key employees" within the nonprofit. Grants are the government grants received. The administrative ratio is administrative expenses divided by total expenses. The fundraising ratio is fundraising expenses divided by direct and indirect public support. 
Table 3: Yearly Summary Statistics

\begin{tabular}{lcc}
\hline \hline \multicolumn{1}{c}{ Variable } & Mean & Std. Dev. \\
\hline Contributions 1998 & 1,336 & 3,985 \\
Contributions 2000 & 1,908 & 5,181 \\
Contributions 2002 & 1,824 & 4,947 \\
Grants 1998 (in thousands) & 2,535 & 20,753 \\
Grants 2000 (in thousands) & 3,048 & 24,446 \\
Grants 2002 (in thousands) & 3,408 & 27,801 \\
Total Expenses 1998 (in thousands) & 23,769 & 233,224 \\
Total Expenses 2000 (in thousands) & 26,694 & 248,801 \\
Total Expenses 2002 (in thousands) & 29,510 & 285,448 \\
Administrative Ratio 1998 & 0.16 & 0.16 \\
Administrative Ratio 2000 & 0.16 & 0.14 \\
Administrative Ratio 2002 & 0.16 & 0.14 \\
Debt Ratio 1998 & 0.07 & 7.37 \\
Debt Ratio 2000 & 0.16 & 20.49 \\
Debt Ratio 2002 & 0.19 & 19.25 \\
Fundraising Ratio 1998 & 0.41 & 17.89 \\
Fundraising Ratio 2000 & 0.44 & 18.77 \\
Fundraising Ratio 2002 & 0.51 & 22.24 \\
\hline \hline
\end{tabular}

This table includes the main variable summary statistics by election cycle using the contemporaneous panel setup. Contributions are the individual contributions by "key employees" within the nonprofit. Grants are the government grants received. The administrative ratio is administrative expenses divided by total expenses. The fundraising ratio is fundraising expenses divided by direct and indirect public support.

Table 4: Main Variable Dummies

\begin{tabular}{|c|c|c|c|}
\cline { 3 - 4 } \multicolumn{2}{c|}{} & \multicolumn{2}{c|}{ Contributions } \\
\cline { 3 - 4 } \multicolumn{2}{c|}{} & 0 & $>0$ \\
\hline \multirow{2}{*}{ Grants } & 0 & 6,760 & 8,836 \\
\cline { 2 - 4 } & $>0$ & 27,910 & 43,326 \\
\hline
\end{tabular}

This table includes dummies for whether contributions and grants are positive or not for each nonprofit per election cycle. 
Table 5: Covariate Correlations

\begin{tabular}{|c|c|c|c|c|c|c|}
\hline & $\begin{array}{c}\tilde{\Xi} \\
\stackrel{\Xi}{\Xi} \\
\stackrel{\Xi}{\Xi} \\
0 \\
0 \\
0 \\
0\end{array}$ & 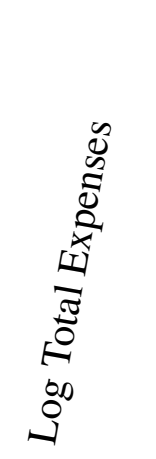 & 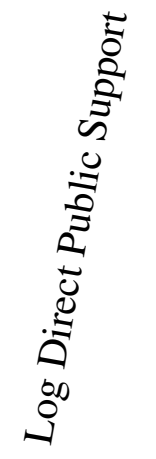 & 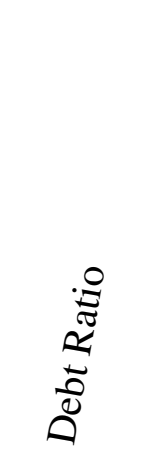 & 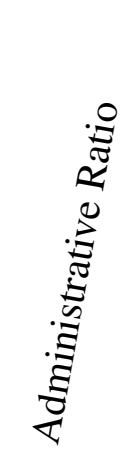 & 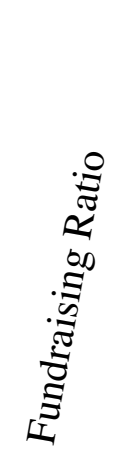 \\
\hline Log Contributions & 1.0000 & & & & & \\
\hline Log Total Expenses & 0.2015 & 1.0000 & & & & \\
\hline Log Direct Public Support & 0.1844 & 0.2862 & 1.0000 & & & \\
\hline Debt Ratio & -0.0030 & 0.0002 & -0.0170 & 1.0000 & & \\
\hline Administrative Ratio & 0.0160 & -0.1259 & 0.0315 & 0.0017 & 1.0000 & \\
\hline Fundraising Ratio & 0.0001 & 0.0229 & -0.0573 & -0.0002 & 0.0027 & 1.0000 \\
\hline
\end{tabular}

This table includes gives the naive correlations between the main covariates. 
Figure 2: Yearly Contribution and Grant Averages

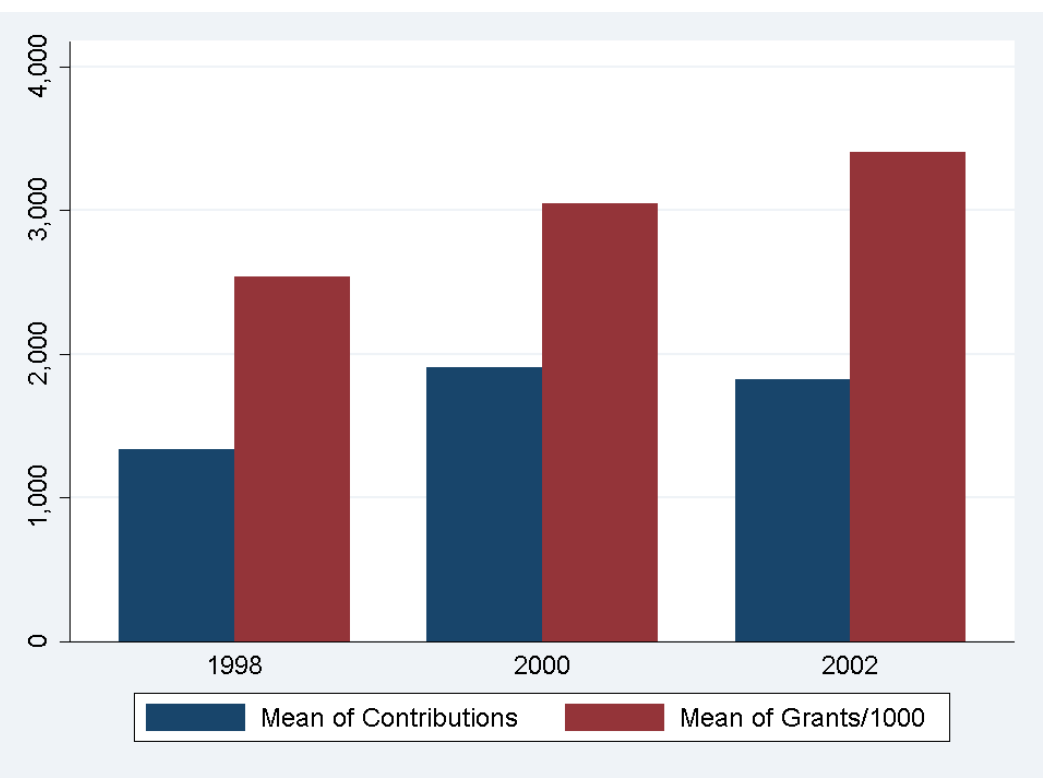

This figure gives a bar graph for the averages of grants and contributions over each election cycle.

Figure 3: Log Grant Histogram

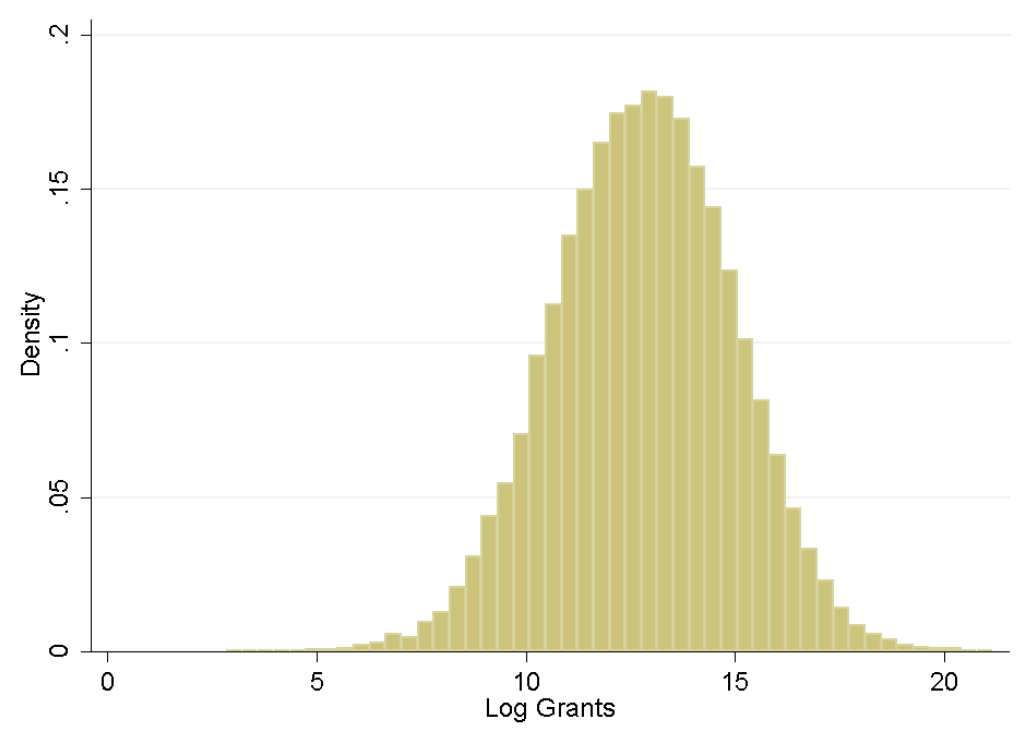

This figure gives the histogram of the natural log of government grants when grants are positive. 
Figure 4: Log Contributions Histogram

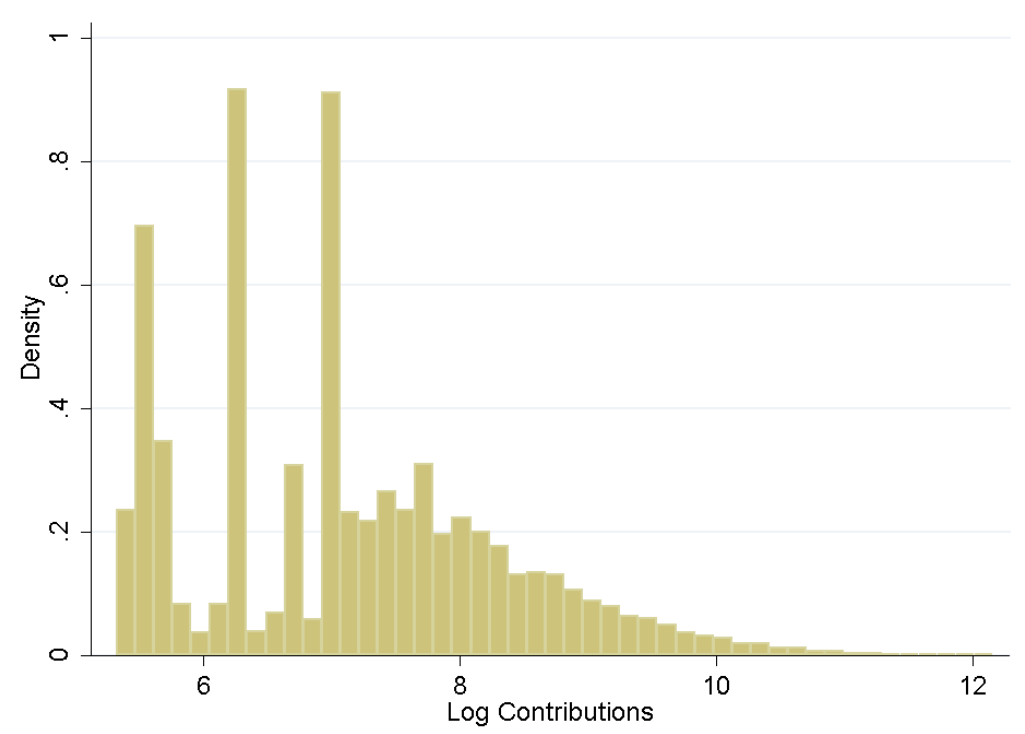

This figure gives the histogram of the natural log of contributions when contributions are positive.

Figure 5: Number of Names Histogram

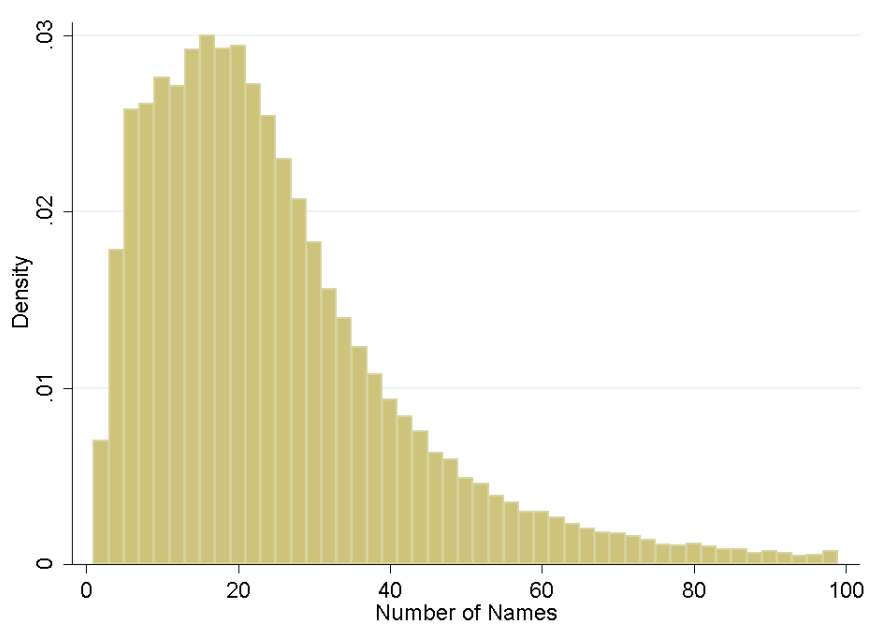

This figure gives the histogram of the number of names listed on audits for nonprofits with fewer than 100 names. 
$\underline{\text { APPENDIX B }}$

REGRESSIONS 
Table 6: Estimating Grants From Pooled Contributions

\begin{tabular}{lccc}
\hline \hline & $(1)$ & $(2)$ & $(3)$ \\
Dependent Variable & Log Grants & Log Grants & Log Grants \\
\hline Log Contributions & $0.045^{* * *}$ & $0.023^{* * *}$ & $0.015^{* *}$ \\
& $(0.005)$ & $(0.005)$ & $(0.005)$ \\
Log Total Expenses & & $1.554^{* * *}$ & $1.459^{* * *}$ \\
& & $(0.064)$ & $(0.065)$ \\
Debt Ratio & & -0.867 & -0.917 \\
& & $(3.444)$ & $(3.343)$ \\
Administrative Ratio & & $2.095^{* * *}$ & $2.092^{* * *}$ \\
& & $(0.277)$ & $(0.275)$ \\
Fundraising Ratio & & $-2.931^{*}$ & $-2.973^{*}$ \\
& & $(1.401)$ & $(1.389)$ \\
\hline Observations & 86832 & 86832 & 86832 \\
\# Nonprofits & 28988 & 28988 & 28988 \\
Adjusted $R^{2}$ & 0.001 & 0.053 & 0.055 \\
Time FE & No & No & Yes \\
Nonprofit FE & Yes & Yes & Yes \\
\hline \hline
\end{tabular}

Robust standard errors clustered at the nonprofit level in parentheses

${ }^{+} p<0.10,{ }^{*} p<0.05,{ }^{* *} p<0.01,{ }^{* * *} p<0.001$

Dependent variable is log government grants to nonprofits. The unit of observation is at the nonprofit election cycle level for the 1998, 2000, and 2002 elections. Yearly nonprofit values are aggregated to the election cycle, with elections matching to concurrent and subsequent nonprofit year values. Entity fixed effects are at the nonprofit level and time fixed effects are at the election cycle level. Contributions are individual campaign contributions by "key employees", total expenses are the nonprofit total operating expenses, debt ratio is the ratio of debts to assets by the nonprofit, administrative ratio is the ratio of administrative costs to total expenses, and fundraising ratio is the ratio of fundraising expenditures to fundraising and public-related revenue (direct public support, indirect public support). 
Table 7: Estimating Grants From Candidate Characteristic Specific Contributions

\begin{tabular}{|c|c|c|}
\hline Dependent Variable & $\begin{array}{c}(1) \\
\text { Log Grants }\end{array}$ & $\begin{array}{c}(2) \\
\text { Log Grants }\end{array}$ \\
\hline Contribution-Lose, Challenger & $\begin{array}{c}0.005 \\
(0.006)\end{array}$ & \\
\hline Contributions-Lose, Incumbent & $\begin{array}{c}0.011 \\
(0.009)\end{array}$ & \\
\hline Contribution-Win, Challenger & $\begin{array}{c}0.014^{*} \\
(0.007)\end{array}$ & \\
\hline Contribution-Win, Incumbent & $\begin{array}{c}0.009 \\
(0.006)\end{array}$ & \\
\hline Contribution-House Candidate & & $\begin{array}{l}0.010^{+} \\
(0.006)\end{array}$ \\
\hline Contribution-Senate Candidate & & $\begin{array}{c}0.013^{*} \\
(0.005)\end{array}$ \\
\hline Contribution-Presidential Cand. & & $\begin{array}{c}-0.004 \\
(0.007)\end{array}$ \\
\hline Log Total Expenses & $\begin{array}{c}1.457^{* * *} \\
(0.066)\end{array}$ & $\begin{array}{c}1.459^{* * *} \\
(0.065)\end{array}$ \\
\hline Debt Ratio & $\begin{array}{c}-0.001 \\
(0.003)\end{array}$ & $\begin{array}{l}-0.001 \\
(0.003)\end{array}$ \\
\hline Administrative Ratio & $\begin{array}{c}2.055^{* * *} \\
(0.278)\end{array}$ & $\begin{array}{c}2.096^{* * *} \\
(0.275)\end{array}$ \\
\hline Fundraising Ratio & $\begin{array}{l}-0.003^{*} \\
(0.001)\end{array}$ & $\begin{array}{c}-0.003^{*} \\
(0.001)\end{array}$ \\
\hline Observations & 84928 & 86832 \\
\hline \# Nonprofits & 28351 & 28988 \\
\hline Adjusted $R^{2}$ & 0.055 & 0.055 \\
\hline Time FE & Yes & Yes \\
\hline Nonprofit FE & Yes & Yes \\
\hline
\end{tabular}

Robust standard errors clustered at the nonprofit level in parentheses

${ }^{+} p<0.10,{ }^{*} p<0.05,{ }^{* *} p<0.01,{ }^{* * *} p<0.001$

Contributions are campaign contributions by "key employees". Debt ratio is debts over assets. Admin ratio is the ratio of administrative costs to total expenses. Fundraising ratio is fundraising costs over public-related revenue. Column 1 is separated by contributions to different types of candidates, grouping candidates into incumbents/challengers, and winners/losers. Losing primary/general are considered the same. Open seat race candidates are all considered challengers. Column 2 is separated by contributions to different types of candidates, grouping candidates into House, Senate, and Presidential races. 
Table 8: Estimating Grants From Contributions By Nonprofit Type

\begin{tabular}{lcccc}
\hline \hline & $(1)$ & $(2)$ & $(3)$ & $(4)$ \\
Type & Large & Small & Arts/Culture & Education \\
\hline Dependent Variable & Log Grants & Log Grants & Log Grants & Log Grants \\
\hline Log Contributions & 0.0066 & $0.0207^{* *}$ & 0.0061 & 0.0216 \\
& $(0.0073)$ & $(0.0070)$ & $(0.0114)$ & $(0.0143)$ \\
Log Total Expenses & $1.8750^{* * *}$ & $1.4415^{* * *}$ & $1.5877^{* * *}$ & $1.6082^{* * *}$ \\
& $(0.1123)$ & $(0.0873)$ & $(0.1316)$ & $(0.1917)$ \\
Debt/Asset Ratio & $4.7774^{* * *}$ & $-9.3001^{* * *}$ & -8.8507 & $0.9897^{* * *}$ \\
& $(0.0463)$ & $(0.6988)$ & $(8.3992)$ & $(0.2215)$ \\
Admin/Total Cost Ratio & $1.1624^{+}$ & $2.5197^{* * *}$ & $3.2347^{* * *}$ & $3.0609^{* * *}$ \\
& $(0.6381)$ & $(0.3192)$ & $(0.4804)$ & $(0.8999)$ \\
Fundraising Ratio & & & & \\
& $-2.0157^{+}$ & $-9.8693^{* * *}$ & $-74.3902^{* * *}$ & -1.3680 \\
& $(1.0472)$ & $(2.6147)$ & $(14.8907)$ & $(9.6759)$ \\
\hline Observations & 41115 & 45717 & 15112 & 9688 \\
\# Nonprofits & 15315 & 17008 & 5047 & 3237 \\
Adjusted $R^{2}$ & 0.025 & 0.068 & 0.076 & 0.074 \\
Time FE & Yes & Yes & Yes & Yes \\
Nonprofit FE & Yes & Yes & Yes & Yes \\
\hline \hline
\end{tabular}

Robust standard errors clustered at the nonprofit level in parentheses

${ }^{+} p<0.10,{ }^{*} p<0.05,{ }^{* *} p<0.01,{ }^{* * *} p<0.001$

Contributions are campaign contributions by "key employees". Debt ratio is debts over assets. Admin ratio is the ratio of administrative costs to total expenses. Fundraising ratio is fundraising costs over public-related revenue. The "type" category here includes small nonprofits (total expenses less than 2 million), large nonprofits (total expenses greater than 2 million), and aggregates the self-reported NTEE codes into 10 major categories. I report the 6 largest. 
Table 9: Estimating Grants From Contributions By Nonprofit Type

\begin{tabular}{lcccc}
\hline \hline & $(1)$ & $(2)$ & $(3)$ & $(4)$ \\
Tyoe & Env/Animals & Health & Human Services & Public Benefit \\
\hline Dependent Variable & Log Grants & Log Grants & Log Grants & Log Grants \\
\hline Log Contributions & $0.0615^{*}$ & 0.0198 & $0.0142^{+}$ & 0.0004 \\
& $(0.0289)$ & $(0.0130)$ & $(0.0076)$ & $(0.0157)$ \\
& & & & \\
Log Total Expenses & $1.6493^{* * *}$ & $1.5989^{* * *}$ & $1.1340^{* * *}$ & $1.6668^{* * *}$ \\
& $(0.4152)$ & $(0.1756)$ & $(0.1033)$ & $(0.1628)$ \\
Debt/Asset Ratio & & & & \\
& $-1.9 \mathrm{e}+03^{*}$ & -0.5066 & $-11.7533^{* * *}$ & $-18.1081^{* * *}$ \\
& $(816.8654)$ & $(3.4945)$ & $(3.4528)$ & $(5.2269)$ \\
Admin/Total Cost Ratio & $2.7804^{*}$ & 1.1009 & $1.1688^{*}$ & $1.9997^{* *}$ \\
& $(1.2345)$ & $(0.8514)$ & $(0.5314)$ & $(0.6535)$ \\
Fundraising Ratio & & & & \\
& $-44.7238^{* * *}$ & -0.7023 & $-8.2526^{+}$ & -2.2908 \\
& $(11.9582)$ & $(2.1426)$ & $(4.4321)$ & $(1.6863)$ \\
\hline Observations & 3222 & 15255 & 32078 & 9665 \\
\# Nonprofits & 1075 & 5090 & 10707 & 3228 \\
Adjusted $R^{2}$ & 0.084 & 0.057 & 0.034 & 0.075 \\
Time FE & Yes & Yes & Yes & Yes \\
Nonprofit FE & Yes & Yes & Yes & Yes \\
\hline \hline
\end{tabular}

Robust standard errors clustered at the nonprofit level in parentheses

$+p<0.10,{ }^{*} p<0.05,{ }^{* *} p<0.01,{ }^{* * *} p<0.001$

Contributions are campaign contributions by "key employees". Debt ratio is debts over assets. Admin ratio is the ratio of administrative costs to total expenses. Fundraising ratio is fundraising costs over public-related revenue. The "type" category aggregates the self-reported NTEE codes into 10 major categories. I report the 6 largest. 
Table 10: Estimating Grants From Contributions Using Alternative Specifications

\begin{tabular}{|c|c|c|c|}
\hline Restriction & $\begin{array}{c}(1) \\
\text { Level }\end{array}$ & $\begin{array}{c}(2) \\
\text { State-Cycle }\end{array}$ & $\begin{array}{c}(3) \\
<5,000\end{array}$ \\
\hline Dependent Variable & Grants & Log Grants & Log Grants \\
\hline Contributions & $\begin{array}{l}54.6529^{*} \\
(27.8149)\end{array}$ & & \\
\hline Log Contributions & & $\begin{array}{l}0.0150^{* *} \\
(0.0055)\end{array}$ & $\begin{array}{l}0.0152^{* *} \\
(0.0050)\end{array}$ \\
\hline Total Expenses & $\begin{array}{l}0.0353^{* *} \\
(0.0114)\end{array}$ & & \\
\hline Log Total Expenses & & $\begin{array}{c}1.4702^{* * *} \\
(0.0705)\end{array}$ & $\begin{array}{c}1.4592^{* * *} \\
(0.0648)\end{array}$ \\
\hline Debt/Asset Ratio & $\begin{array}{c}1.5 \mathrm{e}+05 \\
(2.4 \mathrm{e}+05)\end{array}$ & $\begin{array}{l}-1.0015 \\
(3.3847)\end{array}$ & $\begin{array}{l}-0.0009 \\
(0.0033)\end{array}$ \\
\hline Admin/Total Cost Ratio & $\begin{array}{l}-1.1 \mathrm{e}+06^{*} \\
(5.3 \mathrm{e}+05)\end{array}$ & $\begin{array}{c}2.1058^{* * *} \\
(0.2906)\end{array}$ & $\begin{array}{c}2.0924^{* * *} \\
(0.2746)\end{array}$ \\
\hline Fundraising Ratio & $\begin{array}{c}6.0 e+06 \\
(4.6 e+06)\end{array}$ & $\begin{array}{l}-3.0282^{*} \\
(1.3748)\end{array}$ & $\begin{array}{l}-0.0030^{*} \\
(0.0014)\end{array}$ \\
\hline Observations & 86832 & 75724 & 86823 \\
\hline \# Nonprofits & 28988 & 25281 & 28985 \\
\hline Adjusted $R^{2}$ & 0.072 & 0.056 & 0.055 \\
\hline Time FE & Yes & Yes & Yes \\
\hline Nonprofit FE & Yes & Yes & Yes \\
\hline
\end{tabular}

Robust standard errors clustered at the nonprofit level in parentheses

$+p<0.10,{ }^{*} p<0.05,{ }^{* *} p<0.01,{ }^{* * *} p<0.001$

Contributions are campaign contributions by "key employees". Debt ratio is debts over assets. Admin ratio is the ratio of administrative costs to total expenses. Fundraising ratio is fundraising costs over public-related revenue. The level restriction uses level values of the variables. The StateCycle restriction includes state specific year fixed effects. The $<5,000$ restriction only considers contributions smaller than $\$ 5,000$ per individual per election. 
Table 11: Alternate Specifications Investigating The Number of Key Employees

\begin{tabular}{|c|c|c|c|}
\hline & $(1)$ & $(2)$ & $(3)$ \\
\hline Restriction & Employees & Sample & Employees \\
\hline Dependent Variable & \# of Names & Log Grants & Log Grants \\
\hline \multirow[t]{2}{*}{ Log Contributions } & & $0.016^{* *}$ & $0.015^{* *}$ \\
\hline & & $(0.005)$ & $(0.005)$ \\
\hline \multirow[t]{2}{*}{ Log Total Expenses } & $2.043^{* * *}$ & $1.459^{* * *}$ & $1.444^{* * *}$ \\
\hline & $(0.155)$ & $(0.066)$ & $(0.067)$ \\
\hline \multirow[t]{2}{*}{ Log Direct Public Support } & $0.120^{* * *}$ & & \\
\hline & $(0.029)$ & & \\
\hline \multirow[t]{2}{*}{ Debt/Asset Ratio } & $-0.005^{* * *}$ & -0.001 & -0.836 \\
\hline & $(0.001)$ & $(0.003)$ & $(3.341)$ \\
\hline \multirow[t]{2}{*}{ Admin/Total Cost Ratio } & -0.226 & $2.070^{* * *}$ & $2.234^{* * *}$ \\
\hline & $(0.627)$ & $(0.276)$ & $(0.279)$ \\
\hline \multirow[t]{2}{*}{ Fundraising Ratio } & 0.004 & $-0.003^{*}$ & $-3.300^{*}$ \\
\hline & $(0.004)$ & $(0.001)$ & $(1.579)$ \\
\hline \multirow[t]{2}{*}{ \# of Employees } & $1.353^{* * *}$ & & $0.116^{* * *}$ \\
\hline & $(0.401)$ & & $(0.035)$ \\
\hline \multirow{2}{*}{\multicolumn{2}{|c|}{$\begin{array}{l}\text { \# of Key Employees } \\
\text { (Same as \# of Names) }\end{array}$}} & & $0.003^{*}$ \\
\hline & & & $(0.001)$ \\
\hline Observations & 84200 & 86150 & 84205 \\
\hline \# Nonprofits & 28329 & 28763 & 28329 \\
\hline Adjusted $R^{2}$ & 0.024 & 0.055 & 0.054 \\
\hline Time FE & Yes & Yes & Yes \\
\hline Nonprofit FE & Yes & Yes & Yes \\
\hline
\end{tabular}

Robust standard errors clustered at the nonprofit level in parentheses

${ }^{+} p<0.10,{ }^{*} p<0.05,{ }^{* *} p<0.01,{ }^{* * *} p<0.001$

Contributions are campaign contributions by "key employees". Debt ratio is debts over assets. Admin ratio is the ratio of administrative costs to total expenses. Fundraising ratio is fundraising costs over public-related revenue. I divide the employees variable by 1000 . The "Employees" restriction only considers nonprofits that report the \# employees variable. The sample restriction takes random samples of 25 names from each nonprofit audit and only looks at their contributions. 